\title{
Impact of sodium-selenate on the growth of radish (Raphanus sativus L.) seedlings in vitro
}

\author{
Domokos-Szabolcsy É. ${ }^{1}$, Holb $I^{2}{ }^{2}$, Prokisch $\mathbf{J}^{3}$., Kovács $\mathrm{B}^{3}$., Veres Zs. ${ }^{1}$ and Fári M.G. ${ }^{1}$ \\ ${ }^{I}$ University of Debrecen Centre of Agricultural Sciences, Faculty of Agricultural Sciences, \\ Department of Vegetable Production, 4032 Debrecen, Böszörményi út 138., Hungary; \\ ${ }^{2}$ University of Debrecen Centre of Agricultural Sciences, Faculty of Agricultural Sciences, \\ Department of Plant Protection; \\ ${ }^{3}$ University of Debrecen Centre of Agricultural Sciences, Faculty of Agricultural Sciences, \\ Department of Agricultural Produce Processing and Qualification (szabolcsy@agr.unideb.hu)
}

\begin{abstract}
Summary: Selenium (Se) is an essential trace element for animals, microorganisms and some other Eukaryotes. It has become increasingly evident that Se plays a significant role in reducing the incidence of lung, colorectal and prostate cancer in humans. Although it is well known that some species among higher plants are able to accumulate selenium in their tissues, but others are not able to do so, and there is evidence that selenium is needed for the growth of algae, meanwhile the question of essentiality of Se in vascular plants is unresolved. We aimed to study the in vitro growing and to characterise some physiological properties in radish (Raphanus sativus L.) seedlings treated with 0 to $200 \mathrm{mg} / \mathrm{l}$ sodium-selenate. The results showed that lower $(2 \mathrm{mg} / \mathrm{l})$ concentration sodium-selenate increased the biomass as well as the total antioxidant capacity of seedlings. The seedling's selenium content showed linear correlation with the sodium-selenate content of the medium.
\end{abstract}

Key words: selenium, sodium-selenate, in vitro, photoautotrophic culture, radish (Raphanus sativus L.)

\section{Introduction}

Selenium is a trace element invariably available in living beings of lower and higher order, it incorporates in sulphurous amino-acids, in the place of sulphur (Whanger, 2002). Selenoproteins that have come into existence are mainly the ingredients of enzyme proteins (Standtman, 1990). In animal life, among Vertebrate animals, selenium is vital, constituting an ingredient of several enzymes (Ursini et al., 1995), which are responsible for the normal operation of metabolic processes (Cser et al., 1998). At the same time we know little about the role it plays in Higher plants. That much is known for sure that there are selenium-accumulating, socalled selenophor species (e. g. Astragalus sp.), which benefit from such capability where the selenium content of soil reaches a toxic level (Terry et al., 2000). Apart from this, such plant species (e. g. Allium tricoccum) are also known, which make use of the selenium's repellent impact to keep off certain pests (Birringer, 2002). Nevertheless, there is no unambiguous evidence in the technical literature of the essentiality of selenium in the metabolic processes of Higher plants (Eshdat, 1997). According to scientific papers, radish is a selenium-accumulating species (Hanson et al., 2003). In our experiments we sought an answer to the question as to how sodium-selenate of different concentration, added to culture-medium, influence the growth of radish seedlings in vitro in a photoautotrophic culture system where seedlings are able to assimilate at the effect of light even without external carbohydrate source.[

\section{Material and method}

We conducted the sterile sowing of radish (Raphanus sativus L. cv. Springtime Red) in transparent platic tissue culture box, using 100 seeds for each. Surface sterilisation of the seeds took place in $30 \%$ Chlorox solution for 30 minutes, followed by soaking for two 10-minute periods in sterile ionfree water (Arium 611DI, Sartorius, Germany). We adopted two sorts of culture-media. Culture medium of the first series: we prepared an $\mathrm{Na}_{2} \mathrm{SeO}_{4}$ solution of $0,2,10,50,100$, $200 \mathrm{mg} / \mathrm{l}$ dissolved in ion-free water and solidified it with the use of Plant agar (Duchefa, Biochemie B.V., the Netherlands). We shall use the abbreviation "DW" for this culture medium series hereinafter. Culture medium of the second series: we complemented the sodium-selenate solution having a concentration of $0,2,10,50,100,200 \mathrm{mg} / \mathrm{l}$ with a pre-produced half-strenght Murashige-Skoog (1962) medium (Duchefa, Biochemie B.V., the Netherlands) elaborated for in vitro cultivation, which is called "MS1/2" hereinafter. Germination of the seeds took place on a tissue culture shelf using illumination of 2,500 lux for daily 16 
hours, at a temperature of $23{ }^{\circ} \mathrm{C}$. Seven-day-old seedlings were cut apart by us into shoot and root sections. Treatment by treatment, we measured the fresh mass of 20 individuals each, separately. We fixed the samples by freezing and drying them with the use of a lyophiliser Alpha 1-4 LSC (Christ, Germany). We measured the dry mass, then pounded them into powder in a mortar and stored at $-18^{\circ} \mathrm{C}$. We identified the selenium content of the seedling parts by means of a plasma mass spectrometer of Inductive Coupling, type X7, manufactured by Thermo Elemental (ICP-MS, England). We wondered if increased selenium content in the culture medium would influence the physiological condition of the samples. To this end, we measured the total antioxidant capacity of water-soluble (ACW) and lipidsoluble (ACL) compounds of seedling parts, respectively, by using Photochem chemiluminometer (Analytik Jena AG, Germany).

\section{Results}

\section{Fresh mass of radish seedlings}

We established that the average fresh mass of the shoot in a culture medium of $2 \mathrm{mg} / \mathrm{l}$ of $\mathrm{Na}_{2} \mathrm{SeO}_{4}$ content increased by $4.51 \%$ (DW culture-medium) and by $16.95 \%$ (MS ${ }^{1 / 2}$ culturemedium) in relation to the control group. At $\mathrm{Na}_{2} \mathrm{SeO}_{4}$ concentration of $10 \mathrm{mg} / \mathrm{l}$, we obtained nearly identical mass values in both culture-media in relation to the control group. And from $\mathrm{Na}_{2} \mathrm{SeO}_{4}$ concentration of $50 \mathrm{mg} / \mathrm{l}$ onward, the shoor mass of the individuals significantly diminished in culture media DW and MS1/2 alike (Figure I). In examining the root, in a DW culture medium containing $2 \mathrm{mg} / \mathrm{l}$ of $\mathrm{Na}_{2} \mathrm{SeO}_{4}$, fresh mass increased by $47.2 \%$ compared to the control group, and, in a DW culture medium with a concentration over $10 \mathrm{mg} / \mathrm{l}$ of $\mathrm{Na}_{2} \mathrm{SeO}_{4}$, fresh mass gradually diminished. In an $\mathrm{MS}^{1 / 2}$ culture-medium, at the impact of $2 \mathrm{mg} / \mathrm{l}$ of $\mathrm{Na}_{2} \mathrm{SeO}_{4}$, the root's fresh mass increased by $22.7 \%$ compared with the control group; we only noticed significant decrease in mass with the $\mathrm{MS}^{1 / 2}$ culture medium containing $200 \mathrm{mg} / \mathrm{l}$ of $\mathrm{Na}_{2} \mathrm{SeO}_{4}$.

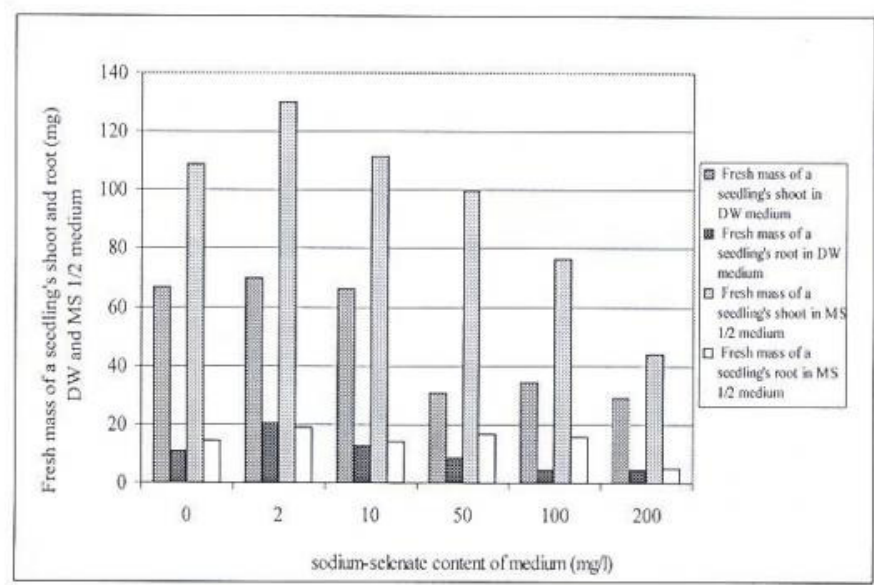

Figure 1 Average mass of shoots and roots of in vitro grown photoautotrophic 'Springtime Red' radish seedlings in DW and $\mathrm{MS}^{1 / 2}$ culture media

\section{Selenium content of radish seedlings}

With the rise of $\mathrm{Na}_{2} \mathrm{SeO}_{4}$ content of the culture medium, the selenium content of the root and shoot invariably increases in the radish seedlings in DW and $\mathrm{MS}^{1 / 2} 2$ culture media (Figure 2). Also, the diagram clearly demonstrates that the selenium content of the root is higher than that of the shoot in both culture media, which may result from the fact that the plant absorbs selenium from the culture-medium through its roots and a part of the selenium may be accumulated in there.

\section{Total antioxidant capacity of radish seedlings}

The water-soluble total antioxidant activity values $(\mathrm{ACW})$ were, in both culture media, lower than the liposoluble total antioxidant values (ACL) (Figure 3). The amount of the ACW showed the maximum value with a culture-medium containing 2 to $10 \mathrm{mg} / \mathrm{l}$ of $\mathrm{Na}_{2} \mathrm{SeO}_{4}$, which, compared to the results of fresh weight measurements, it can

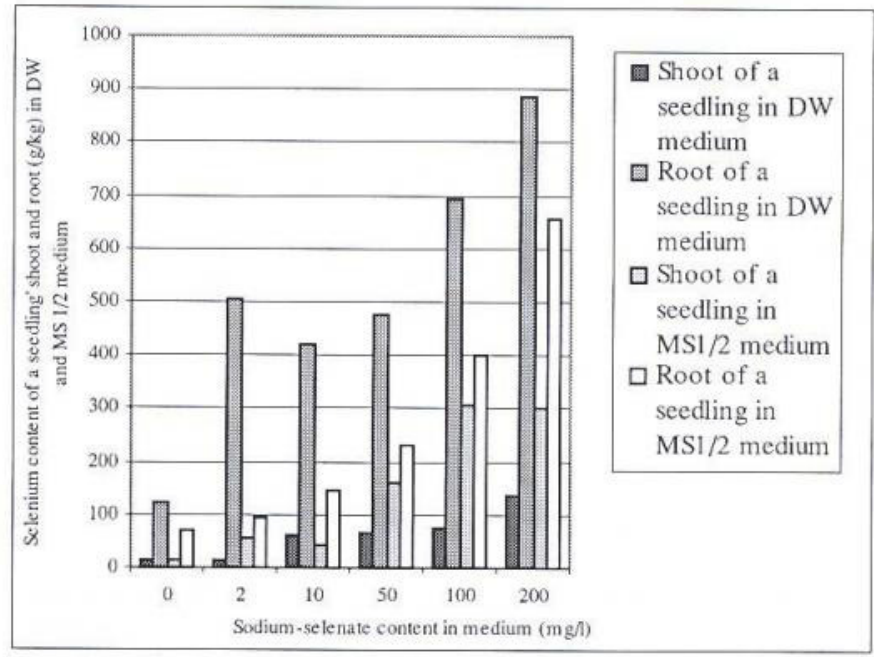

Figure 2 Selenium content of shoots and roots of in vitro grown photoautotrophic 'Springtime Red' radish seedlings in DW and $\mathrm{MS}^{1 / 2}$ culture media

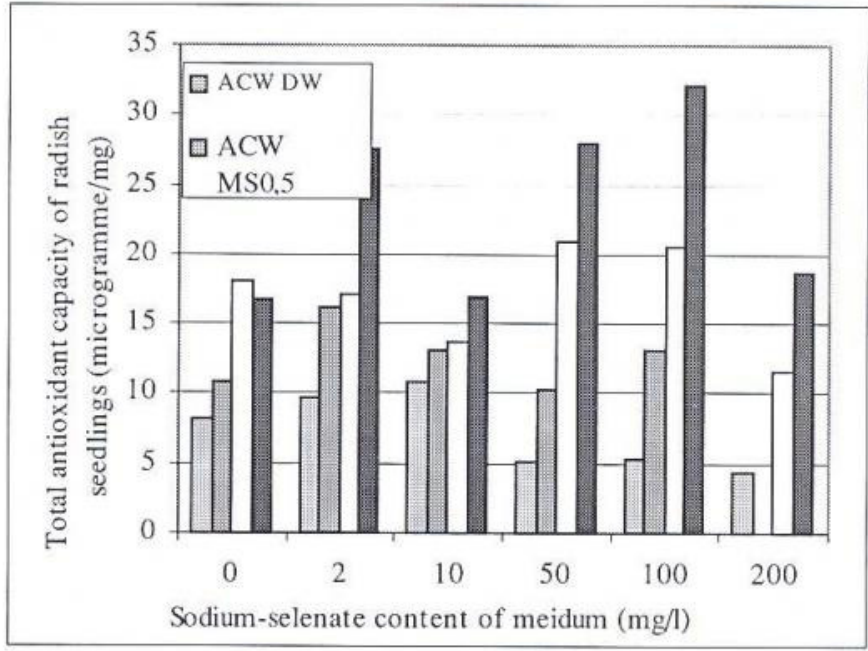

Figure 3 Total water-soluble antioxidant capacity (ACW) and liposoluble (ACL) in vitro grown photoautotrophic 'Springtime Red' radish seedlings 


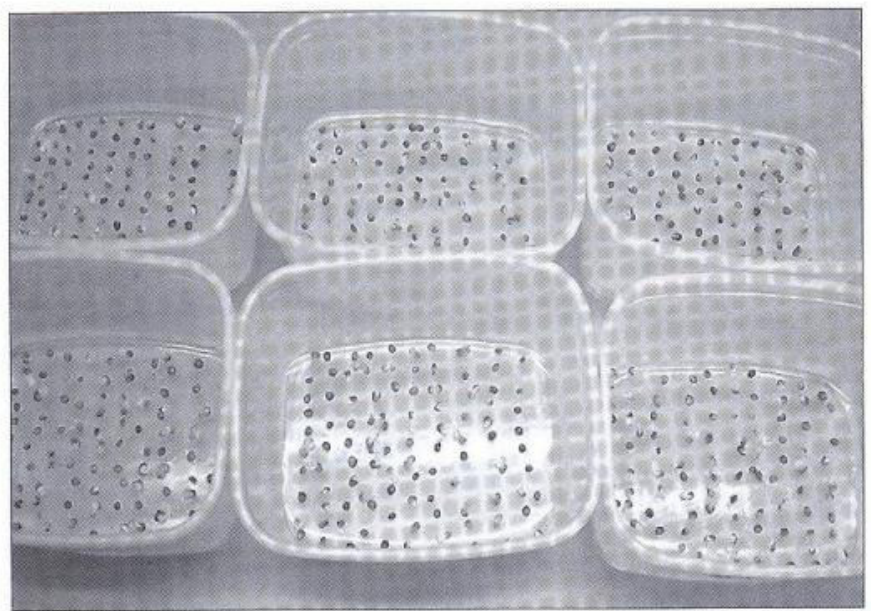

Figure 4 Germination of 'Springtime Red' radish seedligs in transparent plastic tissue culture box

be concluded that this concentration range has a favourable impact on the growth and physiological condition of the radish seedling. Contrary to this, the total liposoluble antioxidant activity showed even two maximum values: in a culture medium containing $2 \mathrm{mg} / \mathrm{l}$ of $\mathrm{NaSeO}_{4}$, selenium is likely to stimulate the endogenous abiotic stress resistance status of the plant. We experienced that a concentration range of 50 to 100 $\mathrm{mg} / \mathrm{l}$ of $\mathrm{Na}_{2} \mathrm{SeO}_{4}$ already had an inhibitory impact on the development of radish seedlings, thus, the increased ACL activity might well protect against a toxic selenium level.

\section{Conclusion}

In our investigations we obsereved a significant difference between the growth of photoautotrophic radish seedlings in vitro grown in $\mathrm{DW}$ and $\mathrm{MS}^{1 / 2}$ culture media having a concentration of 0 to $200 \mathrm{mg} / \mathrm{l}$ of $\mathrm{Na}_{2} \mathrm{SeO}_{4}$. We established that a concentration of $2 \mathrm{mg} / \mathrm{l}$ of $\mathrm{Na}_{2} \mathrm{SeO}_{4}$ had a stimulating impact on the fresh weight of radish seedlings in both culture-media. In this range, the fresh weight of radish seedlings grown in $\mathrm{MS}^{1 / 2}$ culture-medium was by $12.4 \%$ more than that of the seedlings grown in DW culture medium. Presumably, this observation correlates with the favourable impact of mineral and other substances absorbed in an exogenous manner from the culture medium in the course of germination, namely, in the case of DW culture medium only endogenous substances stored in the tissue of the seed were available. During the measuring of the total antioxidant capacity of radish seedlings, it can be concluded from the maximum of the amount of total water-soluble (ACW) and liposoluble (ACL) antioxidant activity with a concentration of $2 \mathrm{mg} / \mathrm{l}$ of $\mathrm{Na}_{2} \mathrm{SeO}_{4}$ that, under in vitro photoautotrophic conditions, the adopted rather low concentration of selenium is advantageous to the physiological conditions of the seedlings. At the same time, the second maximum value measured in the inhibitory range in the ACL examination can be explained by the fact that the accumulation of liposoluble antioxidant substances may compensate the toxic effect of the selenium. Nevertheless, we have found no information hereto in the technical literature. Studying the in vitro morpho-

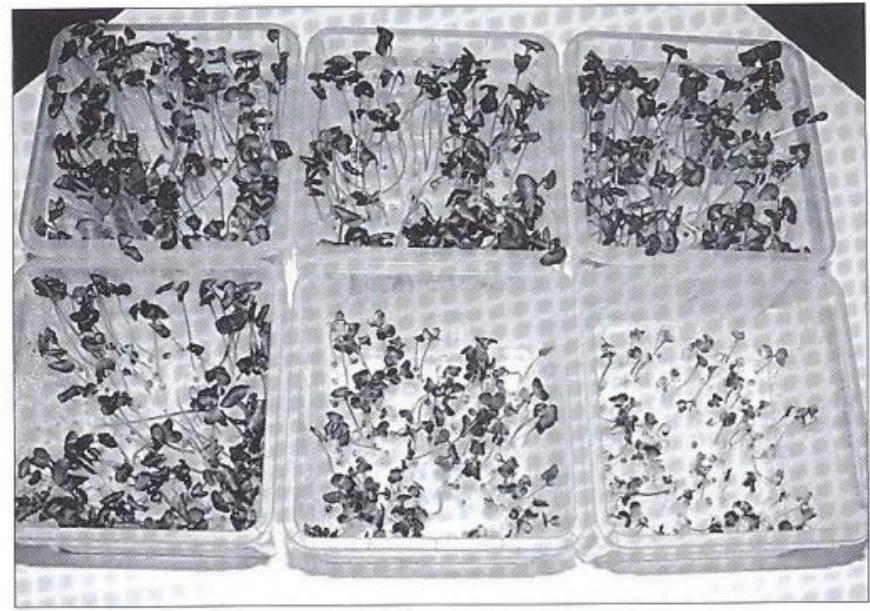

Figure 5 Seven-day-old in vitro 'Springtime Red' radish seedligs

genesis of seedlings treated with selenium in detail is in progress in our laboratory.

\section{Acknowledgements}

This article was produced partly with the use of the support granted by the University of Debrecen Centre of Agricultural Sciences, Interdisciplinary Doctor's School of Agricultural and Natural Sciences (Debrecen, Hungary. Headed by: Prof. Dr. János Nagy), partly with the support granted by the research programme entitled GENOMNANOTECH - (GND, Debrecen, Hungary, Headed by: Prof. Dr. László Fésûs) No. RET-06/2004 of the National Research and Technological Office (NKTH, Budapest, Hungary). The authors express their thanks to Sándor Marosi, university student (University of Debrecen Centre of Agricultural Sciences, Debrecen, Tormay Special College), for his technical assistance rendered in the laboratory.

\section{References}

Birringer, M., Pilawa, S. \& Flohé, L. (2002): Trends in selenium biochemistry. Nat. Prod. Rep. 19: 693-718.

Cser M.Á. \& Sziklai-László, I. (1998): The role of selenium in the environment and health protection. Congress, Budapest, Hungary. Sumaries, 28-45. (In Hungarian)

Eshdat, Y., Holland, D., Faltin, Z. \& Ben-Hayyim, G. (1997): Plant gluthatione peroxidase Physiol. Plant. 100: 234-240.

Hanson, B., Garifullina, G.F., Lindblom, S.D., Wangeline, A., Ackley, A., Kramer, K., Norton, A.P., Lawrence, C.B. \& PilonSmits, A.H. (2003): Selenium accumulation protects Brassica juncea from intervertebrate herbivory and fungal infection. New Phytologist. 159: 461-469.

Standtman, T.C. (1990): Selenium biochemistry. Ann. Rev. Biochem., 59: 111-127.

Terry, N., Zayed, A.M., de Souza, M. \& Tarun, A.S. (2000): Selenium in higher plants Annu. Rev.Plant Mol. Biol. 51: 401-432. Ursini, F., Maiorino, M., Brigeliusflohe, R., Aumann, K.D., Roveri, A., Schomburg, D. \& Flohe, L. (1995): Diversity of glutation peroxidases. Meth. Enzymol. 252: 38-53.

Whanger, P.D. (2002): Selenocompounds in plants and animals and their significance J. Am. Coll. Nutr. 21(3): 223-232. 